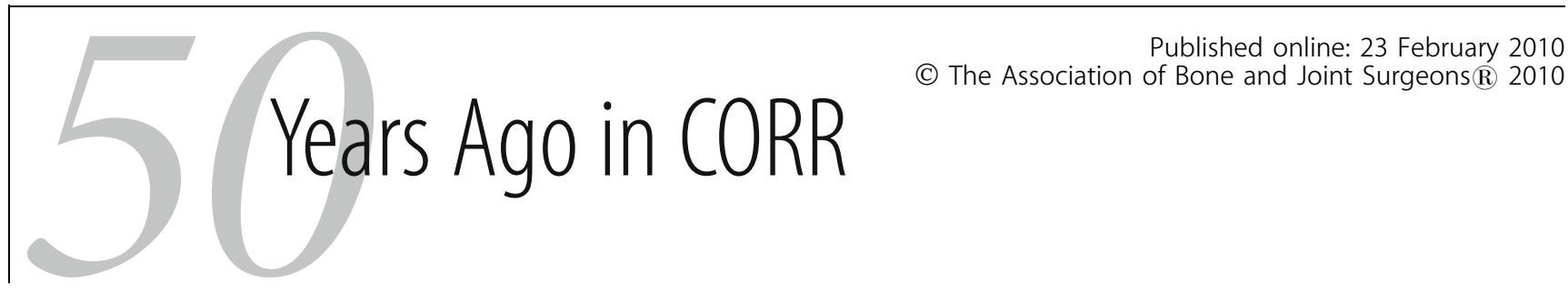

\title{
The Cushion-Socket Below-Knee Prosthesis
}

\author{
Eugene M. Burgess MD and Eugene Coleman CP CORR 1960;16:304-307
}

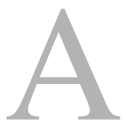

mputations, whether accidental or intentional, have always been a part of human life. The first recorded attempts to fit missing parts of limbs with artificial parts (prostheses) were in ancient Graeco-Roman times [1]: a wooden leg from Southern Italy dated to about 300 $\mathrm{BC}$ is in the Museum of the Royal College of Surgeons in London. However, more sophisticated attempts date to the time of Ambroise Paré (15101590), the famous French military surgeon who not only created a number of clever devices for fitting missing limbs, but introduced the concept of tying arteries with ligature during amputation, rather than cauterization. While many advances were made in terms of concepts and materials, most prostheses were not entirely satisfactory at the time Burgess and Coleman describe belowknee prostheses in CORR in 1960 [2]. They commented,

"In our experience, no belowknee amputee is ever completely happy with the fit and the comfort of his limb. Of course, the basic problem has to do with the necessity for weight-bearing below and about the knee, which area is neither by function nor by anatomy designed for such purpose."

Burgess and Coleman proposed a new type of socket on the prosthesis body (Fig. 1) with a removable cushion (Fig. 2) to provide "wider, local distribution of weight-bearing..." and combined with a thigh cuff that could "assume as much as 50 per

cent of the total weight load." They used the device initially only for "certain difficult cases," and believed that the principle of the cushion socket

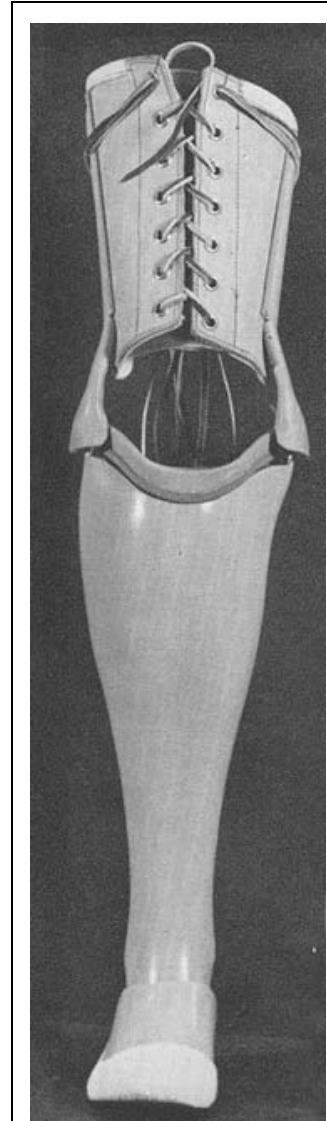

Fig. 1 (Reprinted with permission and (C) Lippincott Williams and Wilkins from Burgess EM, Coleman E. The cushion-socket belowknee prothesis. Clin Orthop Relat Res. 1960;16:304-307.)

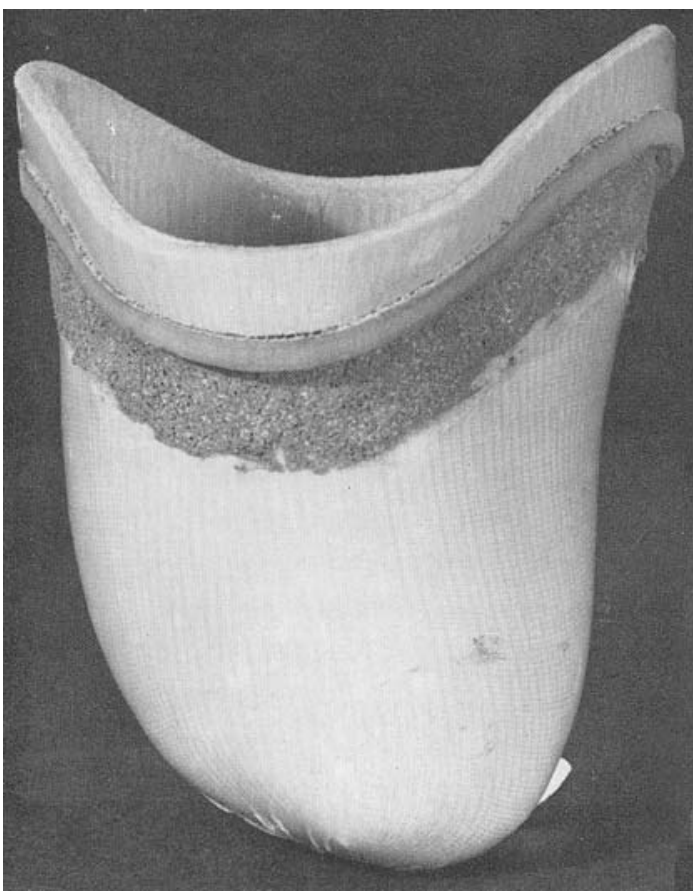

Fig. 2 (Reprinted with permission and (C) Lippincott Williams and Wilkins from Burgess EM, Coleman E. The cushion-socket below-knee prothesis. Clin Orthop Relat Res. 1960;16:304-307.) 


\section{Years Ago in CORR}

was a valuable one and could be extended for other indications [2].

The design and fabrication of prostheses has advanced remarkably since 1960. Various new materials and designs help with the distribution of weight and can be fabricated to accommodate a wider range of amputation stumps, including some that are quite short. Modern electronics has allowed the introduction of increasingly sophisticated and miniaturized computer circuitry to control limbs. Sensors, either implantable or built within the prosthesis or prosthesis-patient interface, can rapidly signal the circuitry to initiate various controls on the prosthesis, including motorized controls. The principles of robotics also allow control of prosthetic devices, particularly those in the upper extremity. Amputees with contemporary prostheses participate in vigorous sports, even at the highest competitive levels (eg, the Paralympics). That said, I suspect the comment of Burgess and Coleman still applies: no amputee is likely ever completely happy with their prosthesis, for they can never replicate the function and sensation of the normal limb. Nonetheless, most patients are far more likely to have a more comfortable, more functional, and less restrictive limb today than 50 years ago.

Richard A. Brand MD Editor-in-Chief Clinical Orthopaedics and Related Research

\section{References}

1. Bick EM. Source Book of Orthopaedics. New York, NY: Hafner Publishing Company; 1968.

2. Burgess EM, Coleman E. The cushion-socket below-knee prothesis. Clin Orthop Relat Res. 1960;16:304307.

\section{Years Ago in CORR:}

The Cushion-Socket Below-Knee Prosthesis

Eugene M. Burgess MD and Eugene Coleman CP

Richard A. Brand MD 